\title{
DISCRETE CHOICE MODELS OF LABOUR SUPPLY, BEHAVIOURAL MICROSIMULATION AND THE SPANISH TAX REFORMS*
}

\author{
JOSÉ M. LABEAGA \\ FEDEA and UNED, Madrid (e-mail: jmlabeaga@fedea.es)
}

\section{XISCO OLIVER}

Universitat de les Illes Balears, Palma de Mallorca (e-mail: xisco.oliver@uib.es)

\author{
AMEDEO SPADARO \\ PSE, Paris-Jourdan Sciences Economiques (Joint Research Unit CNRS-EHESS-ENPC-ENS), \\ Paris and Universitat de les Illes Balears, Palma de Mallorca \\ (e-mail: amedeo.spadaro@uib.es)
}

\begin{abstract}
In this paper, we demonstrate the potential of behavioural microsimulation models as powerful tools for the ex ante evaluation of public policies. The subject of our analysis is the impact of recent Spanish Income Tax reforms on efficiency and household and social welfare. We also analyze the likely effects of some basic income - flat tax and vital minimum - flat tax schemes. The analysis is carried out using a microsimulation model in which labour supply is explicitly taken into account. Instead of following the traditional continuous approach (Hausman 1981, 1985a, and 1985b), we estimate the direct utility function using the methodology proposed by Van Soest (1995). Our data come from a sample of Spanish individuals in the 1995 wave of the EC Household Panel. We show that in the Spanish case, the redistribution policies considered have only little impact on the efficiency of the economy. On the contrary, they strongly affect social welfare.
\end{abstract}

Keywords: Microsimulation; Spanish Income Tax; Evaluation of Public Policies; Participation; Labour supply

\footnotetext{
* Corresponding author: Xisco Oliver, Department of Economics, Universitat de les Illes Balears, Ctra. Valldemossa km. 7,5, 07122 Palma de Mallorca, Spain. Email: xisco.oliver@uib.es. We acknowledge financial support from Spanish Government (BEC2002-04294, SEC2002-02606) and Fundación BBVA. The usual disclaimers apply.

JEL Classification numbers: D31, H21, H23, C25, H31, J22
} 


\section{Introduction}

Over the past 20 years, there have been wide-scale changes in the Spanish redistribution system. ${ }^{1}$ Since 1979 , the year of the creation of income tax, two main reforms have been implemented. In 1989, a large-scale reform provided married wage earners with the possibility of making separate tax declarations. The Personal Income Tax (PIT) system was again reformed in 1999, and the subsequent equity and efficiency effects have been subject of both political and academic debate.

The evaluation of the reform has been carried out mainly via arithmetical simulation techniques. Castañer et al. (2000) use the Taxpayers Panel of the Spanish Tax Agency (Panel de Declarantes por IRPF) to examine the implications of the reform in terms of redistribution and welfare. They show that the 1999 scheme reduces total redistribution, mainly through the reduction of tax receipts. Using the European Community Household Panel and the microsimulation model GLADHISPANIA, Oliver and Spadaro (2003) find similar results. Levy and Mercader-Prats (2002) focus on the analysis of the withholding mechanism and the efficiency effects of the new income tax system. They show that the 1999 reform failed to reduce the compliance costs of taxpayers. Sanchís and Sanchís (2001) simulate the new PIT system, taking into account the effects on household consumption of a VAT increase introduced to compensate for the fall in income tax revenue.

The main pitfall of arithmetical analysis is the absence of behavioural reactions. With respect to the labour market, for example, some of the changes introduced by the reform are particularly designed to provide incentives for the participation of certain groups. Even if this is not the case, we may expect some effects on household consumption/labour supply patterns, at least in the medium-long run. The main concern of this paper is to shed some light on these issues by measuring the impact of the reforms on labour supply behaviour and to evaluate their effects on individual and social welfare.

There have been very few attempts to evaluate Spanish PIT reforms including labour supply behavioural reactions (Labeaga and Sanz, 2001, García and Suarez, 2002, Prieto and Alvarez, 2002 and Castañer et al., 2004). In all of these papers, the labour supply model is based on the traditional continuous approach (see Hausman, 1981 and 1985a) that has been recognized to suffer from several problems. One is the lack of identification of the responses of hours to marginal changes in taxes (see, for instance, Van Soest, 1995); another is the

\footnotetext{
${ }^{1}$ An historical description can be found in Cantó et al. (2002).
} 
under-identification of wage effects due to misspecification of dynamic components (see McCurdy, 1992 or Arellano et al., 1999). The principal inconvenience of using this methodology is that the behavioural restrictions it imposes are too strong, requiring that the labour supply function globally satisfies the Slustky conditions. As a result, the estimation results suffer from a lack of robustness, which reduces their usefulness for policy evaluation (see MaCurdy et al., 1990, and MaCurdy, 1992).

Such weaknesses have pushed researchers towards the estimation of total income elasticities (Feldstein, 1995, Auten and Carroll, 1999, Gruber and Saez, 2002) or the estimation of direct utility functions by a discretisation of the labour supply alternatives (Van Soest, 1995, Aaberge et al., 1995, Hoynes, 1996, Bingley and Walker, 1997, Keane and Moffit, 1998 and Blundell et al., 2000). This second approach has been heavily employed in the recent analysis of tax reforms. Since behavioural changes probably occur at the corner or kink points of the labour supply function, this method has the advantage of capturing them, providing the analyst with an estimation of the elasticity at the extensive margin. Moreover, this methodology allows us to avoid the computational and analytical difficulties associated with utility maximization under non-linear and non-convex budget constraints. This is because the budget constraint is now directly modelled in the utility function. It also enables to consider fixed costs, simultaneous participation and the intensity of work choices, as well as spouses' joint labour supply decisions.

An excellent application of behavioural microsimulation based on discrete choice models, which illustrates very well the potential of this approach, is that of Blundell et al. (2000), which evaluates the likely effect of the introduction of the Working Families Tax Credit (WTFC) in the UK. They estimate, separately, a discrete labour supply model for married couples and single parents on a sample of UK households in the Family Resources Survey for 1995 and 1996. The particularity of the model lies in its ability to include childcare costs which vary with hours of work. They then use their results to simulate labour supply responses under the new budget constraint using the TAXBEN microsimulation model developed at the Institute for Fiscal Studies. The results show that the introduction of behavioural responses reduces the estimated cost of the WFTC program by $14 \%$ from its level in the purely arithmetical scenario. This is mostly due to an increase in labour force participation by single mothers. Similar analysis has been carried out to evaluate recent reforms in the US (Hoynes, 1996 and Keane and Moffit, 1998), Italy, Norway and Sweden (Aaberge et al., 2000), the Netherlands (Das and Van Soest, 2000), Germany (Bonin et al., 
2002) and France (Bargain, 2005). A first objective of this paper is, therefore, to provide, for Spain, an estimation of the labour supply reactions under the "discrete choice” framework.

A striking feature of the papers cited above is that policy evaluation is carried out using only the sub-sample for which it is possible to estimate labour supply responses. The inactive population (i.e. pensioners, students, handicapped, etc.) is excluded from the global analysis of the reforms. This feature is somewhat in contradiction with the standard microsimulation practice that, on the contrary, makes substantial efforts to retain all of the population heterogeneity in the evaluation exercise (see Bourguignon and Spadaro, 2005). Moreover structural reform, such as that in 1999 in Spain, covers the whole population and produces global welfare effects that should be incorporated in any evaluation exercise.

In our opinion, one potential solution to these problems is to carry out a microsimulation exercise combining arithmetic and behavioural instruments in order to adjust the after-tax figures and produce results for the population as a whole. This is our second methodological contribution. In this paper, first, we estimate structural labour supply on two sub-samples of potential participants in the labour market (singles and couples). Second, we use the estimation results from the behavioural modules of the microsimulation model to compute the ex post patterns of labour supply (and utility) of these agents. Third, we perform an arithmetical simulation on the remaining part of the population in the sample. This procedure allows us to obtain a global evaluation of both the efficiency and welfare impacts of the reforms considered.

Given the policy implications of the evaluation results, in addition to the 1999 reform, we also consider other hypothetical scenarios inspired by the basic income - flat tax (BIFT) and vital minimum - flat tax (VMFT) philosophies (see Atkinson, 1995). The objective of these exercises is to shed light on the potential of BIFT and VMFT to reduce inequality and to increase social welfare in Spain (see Oliver and Spadaro, 2003).

The structure of the paper is as follows. Section 2 describes the dataset, the microsimulation model and the main features of the systems simulated (1998 PIT, 1999 PIT and the simulated BIFT and VMFT). Section 3 presents the discrete labour supply model, and its econometric specification and estimation. The evaluation of the different policy scenarios is carried out in Section 4, and Section 5 concludes. 


\section{Data, micro-simulation model and main features of redistribution systems}

We use the Spanish data from the European Community Household Panel (ECHP). The last Spanish wave when we constructed the microsimulation model was that of 1995. Given that we are interested in comparing the 1998 and 1999 scenarios, and that the monetary variables in the 1995 wave are from 1994, we update them using the nominal growth rate (inflation plus real growth). To update incomes from 1994 to 1998 we use the factor 1.281; from 1994 to 1999 the updating factor is 1.335. In Table 1 we compare household net income in the 1998 and 1999 ECHP waves (actually available but not yet implemented in the microsimulation model) with that in our updated dataset. After updating net income, we convert to gross income using the micro-simulation model GLADHISPANIA, in which we can compute, from net incomes, social contributions, total income tax and also the monthly amounts that are withheld from income in anticipation of the yearly income tax bill. This is carried out via a fixed-point algorithm which iterates until it reaches the withholdings, income tax and social insurance contribution patterns which best fit the net incomes observed in the data. $^{2}$ The results of the model's calibration are shown in table 2, where they are compared to the corresponding aggregate figures reported in official statistics. The number of households in the database is 6,522. After dropping 102 observations due to missing information about the household head (which we need to compute income tax accurately), we have 6,420 households, representative of the total number of households in the Spanish population (12,068,375 in 1995, source INE). The descriptive statistics of the variables used in the econometric section are given in table 3. The scenarios which we simulate using GLADHISPANIA are described below.

\section{The 1998 and 1999 Spanish direct redistribution systems}

The model replicates social contributions levied on wages (for employers and employees) and on self-employed workers and income taxes. Table 4 sets out the social contribution rates of firms and employees and the maximum and minimum contribution base-rates for 1998 and 1999.

With respect to the 1998 system, the 1999 reform moved from a PIT structure in which individuals' specific conditions were taken into account mainly by means of tax deductions to one in which they are reflected in tax allowances. Some of the 1998 tax deductions were included in the subsistence-level minimum income (i.e. personal and family tax deductions);

\footnotetext{
${ }^{2}$ A full description of the micro-simulation model (GLADHISPANIA), of the dataset and of the net to gross algorithm is contained in Oliver and Spadaro (2004a).
} 
others became tax deductions on different kinds of expenditure (i.e. tax deductions on employee wages) and some were eliminated altogether (i.e. house rentals). Nevertheless, the main feature of the reform (for our purposes) is that the reduction in both tax brackets (from 9 to 6) and tax rates (as can be seen in table 5). In particular maximum and minimum marginal taxes fell asymmetrically: the former was reduced from $56 \%$ to $48 \%$, whilst the latter fell from $20 \%$ to $18 \%$.

\section{The Basic Income- Flat Tax (BIFT) and the Vital Minimum-Flat Tax (VMFT)}

As mentioned above, the debate over the suitability of the reforms to the Spanish redistribution system is still open. Recently, alternative schemes based on a flat tax mechanism have been proposed (Oliver and Spadaro, 2003). The underlying idea is to simplify the tax structure and, at the same time, to introduce a sort of “citizens' income”. In order to explore the ensuing implications on welfare and redistribution, we carry out simulations of the basic income-flat tax reform (BIFT) and the vital minimum-flat tax (VMFT) reforms. Both replace the 1999 PIT leaving the social security contributions scheme unchanged.

The VMFT reform replaces the 1999 PIT with a vital minimum, which consists of a tax allowance per equivalent adult ${ }^{3}$ and a proportional tax on taxable income. The BIFT reform consists of a universal lump-sum transfer, called the "basic income” (i.e. an amount of money that the government allocates to each household, independent of income and status) plus a flat tax on taxable income. As for VMFT, we take into account the number of household members, yielding a basic income per equivalent adult.

The advantages or disadvantages of a VMFT or BIFT scheme are well known in the literature (see Atkinson, 1995); they are described in table 6. The main inconvenience is the labour supply disincentives that a high flat tax may engender. The econometric model used in the next section takes these disincentives into account and quantifies their impact.

We run four simulations for different flat rates. To facilitate the redistribution analysis, the basic income or vital minimum has been chosen to respect the government's budget constraint (with respect to our year of reference, 1999) in an arithmetical framework. In Table 6, we show the four simulated scenarios. We start from the maximum marginal tax rate of the 1999 system (46\%); which allows 4,632 euros of annual basic income per equivalent adult (and 13,997 euros as the vital minimum), and we reduce the flat tax rate to $38 \%, 30 \%$ and

\footnotetext{
${ }^{3}$ The equivalence scale used is the square root of the number of household members.
} 
$25 \%$. Obviously, reducing the flat tax implies reducing the basic income or vital minimum, as shown in table 7.

\section{The labour supply model, econometric methodology and results}

\subsection{The labour supply model}

We assume that individuals derive utility from household income, $y$, and from leisure, $L$ $=T-h$, with $T$ total time available and $h$ hours of work, with the following utility function:

$$
U=U(y, h ; z)
$$

Here $Z$ are individual characteristics. Consumers maximize utility subject to the usual budget constraint, which is defined in terms of gross real wages, $w$, total household non-labour income, $\mu$, and the tax system $T(h, w, \mu, Z)$, where $h=T-L$. If there are no fixed costs, the budget constraint is:

$$
y=w h+\mu-T(h, w, \mu, Z)
$$

where $T(h, w, \mu, Z)$ are tax payments net of benefits, which in the Spanish tax system depend on hours, wages, non-labour income and demographic characteristics. The consumer's problem can then be written as:

$$
\operatorname{Max}_{h} U(y, h, Z) \text { subject to } y \leq \mu+w h-T(\mu, w, h, Z)
$$

The solution to (3) is complex because $T($.) is non-linear, although it is always possible to optimize for a given marginal tax rate and to obtain a parametric Marshallian labour supply function. In the discrete choice approach, instead of estimating the Marshallian labour supply parameters, we start from the specification of utility $U($.) and estimate the parameters of this function. In what follows we assume the flexible quadratic utility function (as in Keane and Moffit, 1998, and Blundell et al., 2000):

$$
U(y, h, Z)=\alpha_{y y} y^{2}+\alpha_{h h} h^{2}+\alpha_{y h} y h+\beta_{y}(Z) y+\beta_{h}(Z) h
$$

for the singles sub-sample, and

$$
\begin{gathered}
U\left(y, h_{m}, h_{f}, Z_{m}, Z_{f}, Z\right)=\alpha_{y y} y^{2}+\alpha_{h m h m} h_{m}^{2}+\alpha_{h f h h_{f}} h_{f}+\alpha_{y h m} y h_{m}+\alpha_{y h f} y h_{f}+\alpha_{h m h f} h_{m} h_{f} \\
+\beta_{y} y+\beta_{h m} h_{m}+\beta_{h f} h_{f}
\end{gathered}
$$

for couples. The variables $h_{i}$ and $Z_{i}, i=m, f$, are, respectively, hours and demographic characteristics of the member $i$ of the couple. The parameters of income and hours may be linear functions of individual demographic characteristics, so that: ${ }^{4}$

\footnotetext{
${ }^{4}$ An hours equation, which is highly non-linear in the parameters, can be derived from this utility function (see Keane and Moffit, 1998). By using the hours equation joint with the budget constraint, it is also possible to recover the indirect utility function.
} 


$$
\begin{aligned}
& \beta_{y}=\beta_{y 0}+\beta^{\prime}{ }_{y} Z \\
& \beta_{h m}=\beta_{h m 0}+\beta_{h m}{ }_{h m} Z_{m} \\
& \beta_{h f}=\beta_{h f}+\beta_{h f}{ }_{h f} Z_{f}
\end{aligned}
$$

These functional forms are easily tractable and, at the same time, allow a wide range of potential behavioural responses. ${ }^{5}$

Another important issue concerns the presence of fixed costs, which can arise for several reasons such as job search, commuting or costs of children. We assume that they depend on observed variables, so that $F C=Z_{f c} \beta_{f c}$, and they should be deducted from income. Individuals thus evaluate utility, $U=U(y-F C, h ; Z)$, for all possible values of income (net of fixed costs). The effect of these costs on each individual (household) depends on observables $Z_{f c}$, whose weights, $\beta_{f c}$, are estimated at the same time as the rest of the parameters of the utility function.

\subsection{Econometric methodology}

We directly estimate the parameters of the utility function (4) or (5) for different subsamples of the Spanish population. We select a sample selection consisting only of wage earners. However, since marital status likely has significant consequences on labour supply (mainly for the wife but also for the husband), we further separate into sub-samples. We estimate the utility function separately for couples (5) and for singles (4). This has effects both on the coefficients and, for instance, on the necessity of including fixed costs. Given that we estimate a discrete choice model, we have first to decide the finite set $h_{i} \in\left\{h^{1}, h^{2}, \ldots, h^{K i}\right\}$, $i=$ male, female, over which individuals choose their hours. The observability rule in a typical multinomial model is:

$$
\begin{aligned}
h_{i} & =h^{1} \text { if } h \leq h^{B}{ }_{1} \\
& =h^{2} \text { if } h^{B}{ }_{1}<h \leq h^{B}{ }_{2} \\
& =h^{K-1} \text { if } h^{B}{ }_{K-1}<h \leq h^{B}{ }_{K-1} \\
& =h^{K} \text { if } h>h^{B}{ }_{K-1}
\end{aligned}
$$

The appropriate number of intervals is evaluated by looking at the histograms of hours for both males and females (see Figure 1). Once we have decided the choice set, we have $K_{i}$

\footnotetext{
${ }^{5}$ See Stern (1986) for a discussion of the properties of these and other functions.
} 
alternative values for hours for agent $i\left(K_{m} \cdot K_{f}\right.$ for the household), which determine the total income of the individual (household):

$$
\begin{aligned}
& y\left[h_{i}\right]=w_{i} h_{i}+\mu-T\left(h_{i}, w_{i}, \mu ; Z_{i}\right) \quad \text { for } \quad h \in\left\{h^{1}, h^{2}, \ldots, h^{K_{i}}\right\} \\
& y\left[h_{m(\cdot)}, h_{f(\cdot)}\right\rfloor=w_{m} h_{m(\cdot)}+w_{f} h_{f(\cdot)}+\mu-T\left(h_{m(\cdot)}, h_{f(\cdot)}, w_{m}, w_{f}, \mu ; Z_{m}, Z_{f}, Z\right)
\end{aligned}
$$

for all possible combinations of $h_{m(.)} \in\left\{h_{m(.)}^{1}, h_{m(.)}^{2}, \ldots, h_{m(.)}^{K m}\right\}$, and $h_{f(.)} \in\left\{h_{f(.)}^{1}, h_{f(.)}^{2}, \ldots\right.$, $\left.h_{f(.)}^{K f}\right\}$. The variables $w_{m}$ and $w_{f}$ are, respectively, gross wages of men and women. The individual (household) maximizes (4) or (5) over the set of hours $h_{i} \in\left\{h^{1}, h^{2}, \ldots, h^{K i}\right\}$. To estimate the model we have to add stochastic terms to the utility function. In what follows, we only add shocks specific to the state or hours regime for each of the possible choices, which we assume are generated by extreme value distributions. Under these assumptions we can derive the choice probability for agent $i$ as:

$$
\begin{aligned}
& \operatorname{Pr}\left[h_{i}=h^{j}, Z\right]=\operatorname{Pr}\left[U_{i^{j}}^{*}>U_{i^{K}}^{*} \text { for all } k \neq j, k \in\{1,2, \ldots, K\}\right] \\
& =\frac{\exp \left[U^{*}\left(y_{i^{j}}, T-h^{j} ; Z\right]\right.}{\sum_{k=1}^{K} \exp \left[U^{*}\left(y_{i^{k}}, T-h^{k} ; Z\right]\right.}
\end{aligned}
$$

where $U^{*}()=.U()+.\varepsilon_{h i}$.

Similarly, for a couple, we can write the joint probability of preferring a combination of hours $\left(h_{m(.)}, h_{f(.)}\right)$ as:

$$
\begin{aligned}
& \operatorname{Pr}\left[h_{m(.)}=h_{m(.)}^{j}, h_{f(.)}=h_{f(.)}^{k}, Z_{m}, Z_{f}, Z\right]=\operatorname{Pr}\left[U_{\left\{h_{m}^{j}, h_{f}^{k}\right\}}^{*}>U_{\left\{h_{m}^{s}, h_{f}^{t}\right\}}^{*} \quad \text { for all } s \neq j, t \neq k\right] \\
& =\frac{\exp \left[U^{*}\left(y\left[h_{m}^{j}, h_{f}^{k}\right], T-h_{m}^{j}, T-h_{f}^{k} ; Z_{m}, Z_{f}, Z\right]\right.}{\sum_{s} \sum_{t} \exp \left[U^{*}\left(y\left[h_{m}^{j}, h_{f}^{k}\right], T-h_{m}^{j}, T-h_{f}^{k} ; Z_{m}, Z_{f}, Z\right]\right.}
\end{aligned}
$$

where $U^{*}\left(\right.$.) is now equal to $U()+.\varepsilon_{h m h f}$. Under the hypothesis of independent errors, we can write the likelihood function $\Phi$ of each model, respectively, as:

$$
\begin{aligned}
& \ln \Phi_{s}=\sum_{i=1}^{N} \sum_{k=1}^{K} d_{k}\left[\ln \operatorname{Pr}\left(h_{i}=h^{k i} ; Z_{i}\right]\right. \\
& \ln \Phi_{c}=\sum_{i=1}^{N} \sum_{k=1}^{K} d_{j k}\left[\ln \operatorname{Pr}\left(h_{m(\cdot)}=h_{m(\cdot)}^{j}, h_{f(\cdot)}=h_{f(\cdot)}^{k} ; Z_{m}, Z_{f}, Z\right]\right.
\end{aligned}
$$

where the sub-indices $s$ and $c$ stand for singles and couples respectively. The variables $d_{k}$ and $d_{j k}$ are $(1,0)$ dummies: $d_{k}=1$ if $\left[h_{i}=h^{k i}\right]$ and $d_{j k}=1$ if $\left[h_{m(.)}=h_{m}^{j}\right.$ and $\left.h_{f(.)}=h_{f}^{k}\right]$. All of the parameters in the utility functions are estimated by maximum likelihood. 


\subsection{The results}

The estimation of the model follows the identification of the set of labour supply alternatives for each individual. This latter is carried out by looking at the data on hours of work (see Aaberge et al., 2005, for example). In Figure $1 a$ we show the distribution of hours of work for singles; Figures $1 b$ and $1 c$ contain, respectively, analogous numbers for the household head (in a couple) and for his/her wife/husband. We observe considerable differences in the non-participation rate between these figures: non-participation of singles is around 20\%; for household heads (in couples), we observe a figure of around 6\%, which however raises to $59 \%$ for his/her spouse.

The mode is similar across the three distributions: in all three a large percentage of observations fall between 35 and 42 hours of work, which corresponds to full-time work in Spain. We set up different choice sets for singles and for the two members of couples, according to these distributions. For singles we construct brackets for 0-4, 5-34, 35-44 and over 44 hours, which correspond to actual hours values (in the utility function) of $0,30,40$ and 50, respectively. For couples, the choice set of the household head is 0,40 and 50, since there is no part-time employment. These choices correspond to the intervals $0-4,5-44$ and more than 44. For the second member of the couple, the " 0 " option corresponds to bracket 0 4 , the option "25" corresponds to the interval 5-34 and the option " 40 " corresponds to the bracket "more than 35 hours of work".

We obtain estimates of the parameters of the utility function for singles (eq. 4) by optimizing (11), and for couples (eq. 5) by optimizing (12). The sub-sample of singles corresponds to households with only one adult with or without children, whereas the subsample of couples corresponds to couples with or without children. We exclude extreme observations as well as individuals (households) who are self-employed or retired. We then estimate the models on sub-samples of potentially active individuals, as shown in table 8.

We consider age, education and number of children ${ }^{6}$ as the observables entering vectors $Z_{m}, Z_{f}$ and $Z$ in equation (6) which capture differences in preferences. In tables 9 and 10, we report the results of the estimations, for the sub-samples of singles and couples respectively, giving the values of the coefficients corresponding to hours of leisure. In general terms the results are consistent with economic theory. The marginal utility of income increases at a decreasing rate and is almost always positive. This concavity is not significantly identified for

\footnotetext{
${ }^{6}$ We also tried additional variables but only kept those with significant coefficients and which did not generate convergence problems. Information on a number of potential determinants of differences in the utility from working at different hour levels, such as variables for region or size of the municipality, is not available in the dataset.
} 
singles. Some demographic variables affecting both income and hours of leisure are significant in the singles specification. In particular, the income effect increases with age and there are significant effects of the common fixed costs on utility. These can be attributed to unobservables such as the cost of looking for work for the unemployed or costs of commuting for workers.

The coefficients in the regression corresponding to couples show that the marginal utility of income is positive for $99 \%$ of the sample and the utility function is concave at standard significance levels. The marginal utility of income is higher the older is the spouse and the younger is the household head. The marginal utility of hours of leisure of the household head is positive while it is negative for the spouse, although it increases with spouse's age, which may suggest that, as women's participation has increased recently, they need to stay in work longer in order to obtain retirement benefits. The effect of hours on marginal utility dominates, and the presence of children does not change it very much. Both low-educated men and women prefer to work more hours. Fixed costs do not seem to affect utility for couples. Although most of these results are similar to those found in the existing literature (see Blundell et al., 2000), some of them also demonstrate the specific nature of the Spanish labour market.

\section{Evaluation of the Spanish reforms: efficiency and welfare effects}

The simulation of the effects of the reforms is carried out at both the individual and the social level. First, we quantify the efficiency costs by looking at changes in household labour supply. Given the discrete nature of the labour supply alternatives, the results are reported in terms of transition matrices (section 4.1). The second step is the identification of winners and losers. This is done by comparing individual utility before and after the reform (section 4.2).

The third and fourth evaluation exercises concern the social welfare effects of each reform. In section 4.3 we compare the scenarios we have simulated, ordering them by a social welfare function which sums individuals' weighted indirect utility. The weights capture the social planner's inequality aversion. Several specifications are tested in order to carry out sensitivity analysis with respect to the social welfare function used.

In section 4.4, an alternative social evaluation method is explored: this is based on a social welfare function which assigns weights to individual utilities measured in terms of equivalent incomes (King 1983). With respect to the previous method, this approach has the advantage of not depending on the cardinalisation of the individual utility function. 


\subsection{Efficiency effects}

One of our main goals is to quantify the efficiency costs (measured in terms of hours of work) of the reforms. The reference scenario is the one in force in 1999. Tables 11 and 12 show the transition matrices for each reform. Rows (i) contain the observed distribution of working hours in 1999, whereas columns (j) show the predicted distribution under each simulated scenario. Each cell $a_{i j}$ of the matrix (for $\mathrm{i} \neq \mathrm{j}$ ) shows the number of individuals (households) changing from the observed alternative $i$ to the predicted alternative $j$. The diagonal elements refer to the number of individuals (households) that do not change the labour supply following the reform.

In table 11 we present the results for the sub-sample of singles. The values to the right of the diagonal reflect individuals who increase their labour supply after the reform and vice versa. The first point to note is that almost all individuals remain on the diagonal, which means that the reforms have only little impact on labour supply. Comparing the 1999 scenario to that in 1998, we observe two individuals who do not work in 1999 worked 40 hours in 1998, and three individuals working 40 hours or more reduce their labour supply (one of whom stops working). Along the same lines, the BIFT-25\% scenario does not affect labour supply much either. This is due to the reduced flat tax and basic income. Three individuals increase their labour supply and three decrease it. The second point is that, as expected, the higher the marginal tax rate, the greater the labour supply effects. Under the BIFT-38\% scenario, average hours of work fall by $3 \%$. Under the BIFT-46\% scenario, $6.2 \%$ of individuals reduce their labour supply (5\% of individuals decide to stop working). The VMFT scheme produces only small labour market disincentives: total working hours remain almost constant.

Table 12 presents the transition matrices for couples. As there are nine possible alternatives, combining hours of work of the household head and his/her spouse, the table is somewhat more complicated. In this case, not all of the elements to the right (left) of the diagonal represent an increase (fall) in total hours of work. We may observe substitution between spouses' working hours. For example, under the scenario BIFT-38\% we observe that 0.5\% of the households ( 5 out of 1,015) move from 0_40 to 40_0: under the 1999 system the household head does not work and the spouse works 40 hours; after the reform the head of the household works 40 hours and the spouse stops working (there is substitution between partners' hours of work). As in the previous case, two facts should be stressed. First, the majority of households are on the diagonal, which implies that, on aggregate, they do not 
change their labour supply. Second, the higher is the marginal tax rate the greater are the labour supply effects.

When comparing the 1998 system to that in 1999 we observe very few changes. We obtain more or less the same results under the scenario VMFT. With a flat tax of $25 \%$ or $30 \%$ there are no households entering or exiting the labour market. With a flat tax of $38 \%$ or $46 \%$ only one household stops working while another starts working. These results are a direct consequence of the estimation of insignificant fixed costs. ${ }^{7}$ The picture is different under BIFT. In terms of total hours of work, the BIFT-38\% reform reduces labour supply by 3\%, while the BIFT-46\% reform reduces hours of work by $4.3 \%$. Again, the extreme case is BIFT$46 \%$, in which $0.6 \%$ of households stop working and $4.7 \%$ clearly reduce their labour supply.

The main conclusion of this analysis is that, on average, the efficiency effects are negligible for all of the scenarios examined and for each household type. The only exceptions are for the BIFT scenarios with high flat tax rates (38\% and 46\%). Here, the average change in labour supply is around 5-6\% (which cannot be considered as "negligible" in terms of the political feasibility of the reform).

\subsection{Winners and losers}

A first approximation of the welfare effects may be obtained by looking at the households whose utility increases after the reform (winners) and those for whom it falls (losers). In each reform there are winners and losers, but their distribution over the income deciles is not uniform. We find out which part of the population benefits or loses by analyzing the distribution over income deciles. Unfortunately, this does not allow us to rank the reforms unequivocally in terms of social welfare.

The utility function is computed using the parameters estimated in section 3. For households that are not potential workers we calculate utility as follows. First, fiscal units are identified, following the criteria established by the Tax Agency (parents and children under 18 or disabled children). If the fiscal unit is a couple, the estimated coefficients for couples are used. On the other hand, if the fiscal unit is composed of one parent, without a spouse, the coefficients for singles are used. The other household members (grandparents, uncles, children over 18...) are treated as singles. The new household typology is shown in table 8. Figure 2 presents the results for the whole sample; winners and losers from each reform are shown by income deciles.

\footnotetext{
${ }^{7}$ Coefficients that are not significant at the $10 \%$ level are dropped from the labour supply equation.
} 
Comparing the 1998 and 1999 systems we see that the 1999 scenario is characterised by more winners than losers but, at the same time, the winners are concentrated at the top of the income distribution. These results are in line with those of Oliver and Spadaro (2004b) showing that the 1999 reform seems to favour rich households.

The VMFT scenarios produce similar results: the poorer deciles (1 to 4 ) are not affected by the reforms. This is because these households are largely exempt from income tax and are thus unaffected by the reform. In the other deciles we find more losers than winners: this is because the marginal tax rate increases. In particular, from the fourth to the seventh or eighth decile the number of winners increases progressively, and then decreases (except for the VMFT-25\% reform, in which the winners represent between 35 and 45\%, starting from the sixth decile). The losers appear in the fifth decile and their number increases progressively (except under VMFT-25\%, where they are fewer in the last decile due to the low marginal tax rate). Except for the VMFT-25\% reform, the number of winners always exceeds the number of losers.

The BIFT reforms affect everyone. Due to the presence of a basic income, the first deciles are composed of winners; the losers are concentrated in the higher deciles. Starting from the fourth and fifth deciles, the number of losers increases progressively. The higher is the basic income given to each household, the higher is the number of winners. From the comparison between the BIFT and the VMFT scenarios, we see that, despite similar effects at higher incomes, the treatment of poor households in the BIFT increases the number of winners. This result can thus be considered as an argument in favour of BIFT.

\subsection{Social welfare evaluation: an optimal taxation approach}

One possible way to analyze the social desirability of the reforms consists in computing, under each of the systems evaluated, a social welfare function assigning a certain weight to each individual depending on the utility they obtain in each of the situations. This approach is typical in the optimal taxation framework (Mirrlees, 1971, Stern, 1976). This procedure has the advantage of summarizing in one number the welfare associated with each reform. However, it does require the specification of a social welfare function, which depends on the particular cardinalisation of the utility function. The social welfare function used here is the following: ${ }^{8}$

\footnotetext{
${ }^{8}$ To decrease the computational burden, the utility for couples and singles has been normalized to their respective means. The results of this section must be interpreted bearing in mind that they are not independent of the particular social welfare function used for the evaluation.
} 


$$
W=\frac{1}{\lambda} \sum U_{s}(y, L, X)^{\lambda}+\frac{1}{\lambda} \sum\left[\pi * U_{c}(y, L, X)\right]^{\lambda}
$$

where $U_{s}$ and $U_{c}$ represent singles' and couples' utility respectively, $\pi$ is a parameter weighting couples' utility in the social welfare function, and $\lambda$ is a parameter in $(-\infty, 1]$, capturing the social planner's aversion to inequality. For $\lambda=1$, the planner puts the same marginal weight on every household (this is the utilitarian specification), while for $\lambda \rightarrow-\infty$ the government is only interested in the welfare of the poorest household (the Rawlsian specification).

The results are shown in Figure 3, in which we set $\pi=2 .^{9}$ On the $\mathrm{x}$-axis, $\lambda$ takes values from -2 (a social welfare function with greater inequality aversion) to 1 (utilitarian). On the yaxis, we show the percentage increase or decrease in social welfare with respect to the reference scenario (1999).

The reform that seems to be optimal ${ }^{10}$ (among the alternatives evaluated), independent of the social planner's inequality aversion, is BIFT-46\%. The effects, in terms of welfare, of a higher basic income dominate the efficiency losses (in terms of labour supply) of a higher tax rate. This is certainly due to the small implicit extensive elasticities estimated in section 3 . Other BIFT reforms with lower marginal tax rates are still more desirable than the VMFT or 1999 systems. The only exception occurs between the BIFT-25\% and the VMFT-46\% and VMFT-38\% for utilitarian specifications of the social welfare function: in these cases the two VMFT schemes yield higher social welfare. The reason is that the lower level of basic income that can be assigned with a marginal tax of $25 \%$ is not sufficient to compensate, in terms of welfare, for the efficiency loss resulting from the higher (25\%) marginal tax rate for poor households ${ }^{11}$.

\subsection{Social welfare evaluation: computing equivalent incomes}

We complete the policy evaluation by computing equivalent incomes. ${ }^{12}$ These allow us to construct a social welfare function in terms of money metric utility that does not depend on the cardinalisation of the utility functions used. ${ }^{13}$ A prior step to computing equivalent incomes is to calculate the equivalent variation for each household. This is defined by the

\footnotetext{
${ }^{9}$ Other plausible values of the $\pi$ parameter yield the same conclusions. These results are available upon request.

${ }^{10}$ In the sense that it yields the maximum value of social welfare.

${ }^{11}$ Similar results are obtained from a separate analysis of couples and singles.

${ }^{12}$ See King (1983) and Creedy and Duncan (2002).

${ }^{13}$ Other money metric utility measures exist, such as the compensating variation or consumer surplus. The advantage of equivalent variation over the other measures is that the reference prices are those pre-reform. This property renders the comparison between the reforms easier.
} 
amount of money that we must give to (or take away from) household $i$ before the reform so that the household is unaffected by the reform. Following the notation in section 3, the equivalent variation of household $i, V E_{i}$, is obtained by solving for $V E_{i}$ in the following equation:

$$
\operatorname{Max}_{j}\left[U\left(y_{i j}^{1}, h_{j}, Z_{i} ; v_{j}\right)+\varepsilon_{i j}\right]=\operatorname{Max}_{k}\left[U\left(y_{i k}^{0}+V E_{i}, h_{k}, Z_{i} ; v_{k}\right)+\varepsilon_{i k}\right]
$$

Here $y_{i s}^{0}$ and $y_{i s}^{1}$ represent disposable income before and after the reform for household $i$ and choice $s$ respectively. Equivalent variation $V E_{i}$ is a variable which depends on the distribution of the error term, disposable income before and after the reform, and household characteristics. The optimal post-reform choice, $j$, is not necessarily the same as choice $k$, the optimal choice with the equivalent variation. ${ }^{14}$ As is often the case in simulation studies, we assume that policy reform does not affect the error terms. A positive (negative) equivalent variation indicates households which increase (decrease) their utility after the reform.

The distribution by income deciles of the equivalent variation for each reform is presented in table 13. Again, the pre-reform scenario is the 1999 system. Table 12 shows that, on average, there is a loss of 200 euros per household under the 1998 system; this figure is larger for the top income deciles. On the contrary, the BIFT schemes produce significant improvements in terms of average welfare: the large positive equivalent variations for the bottom deciles compensate for the losses suffered by the top deciles. The BIFT schemes produce average equivalent variation figures of $1328 €$ (for a tax rate of $46 \%$ ), $953 €(38 \%)$, $581 €(30 \%)$ and $349 €(25 \%)$. Under VMFT schemes, there is a small increase in average welfare resulting from the positive amounts computed for the deciles from 5 to 8-9.

Equivalent incomes, $Y e$, may be computed using the equivalent variation for each household. The equivalent income is defined in terms of indirect utility, $V(\cdot)$, as:

$$
V\left(t_{a}, Y e\right)=V(t, m)
$$

where $t_{a}$ is the reference price. Using the cost function:

$$
Y e=E\left(t_{a}, V\left(t_{b}, m_{b}\right)\right)
$$

where $E(\cdot)$ is the cost function, $t_{a}$ are prices before the reform and $V\left(t_{b}, m_{b}\right)$ is the utility level achieved after the reform. Using the 1999 system as the reference, equivalent income is:

$$
Y e=y^{0}+V E
$$

\footnotetext{
${ }^{14}$ Note that for non-potential worker households (inactive people, the self-employed) the equivalent variation may be computed as the difference in disposable income before and after the reform.
} 
This equivalent income is a measure of the welfare of each agent that does not depend on the cardinalisation of the utility function used. It is then possible to build a social welfare function in the following way:

$$
B S=\frac{1}{N \lambda} \sum(Y e)^{\lambda}
$$

where, as in section $4.3, \lambda$ is a parameter in $(-\infty, 1]$ which captures inequality aversion; $N$ is the number of households.

Figures $4 a$ and $4 b$ show the results for values of $\lambda$ from -2 to 1 . They represent the changes in social welfare (BS) using the system in force in 1999 as the reference scenario. In Figure $4 a$ we compare the 1999, 1998 and VMFT scenarios. In Figure $4 b$ we compare the reference system (1999) and the BIFT scenarios. ${ }^{15}$ The first, and most important, result is that BIFT-46\%, BIFT-38\%, BIFT-30\% and BIFT-25\% yield (in that order) the highest values of social welfare independent of $\lambda$. Comparing Figures $4 a$ and $4 b$ we see that the rise in social welfare associated with BIFT is 50-60 times higher than that from VMFT. The basic incomeflat tax scenarios seem to represent the best trade-off between equity and efficiency. They are much more effective in raising social welfare than a vital minimum-flat tax mechanism, independent of the social planner's aversion to inequality.

The other interesting result is that, with this social welfare evaluation methodology, VMFT schemes, and the 1998 and the 1999 systems produce very similar effects (see Figure $4 a$ ). This is particularly true for social planners who are inequality-averse. The explanation is intuitive: the more Rawlsian the planner the less weight is given to changes at the middle or the top of the distribution. Since VMFT, 1999 and 1998 schemes have similar impacts on poorer households, their evaluation is practically the same.

The fact that this social evaluation technique suggests that basic income flat tax schemes are the most socially desirable redistribution mechanisms reinforces the results obtained in section 4.3: the small labour supply effects and the large increase in the welfare of poor households support the BIFT mechanism as a powerful instrument for income redistribution.

\section{Conclusions}

In this paper we have evaluated the efficiency and welfare effects (both at the individual and social levels) of recent reforms of the Spanish Income Tax system, compared to some BIFT and VMFT alternatives. The analysis is carried out using a microsimulation model in

\footnotetext{
${ }^{15}$ We present the simulation results in two separate Figures in order to make them clearer, given the large difference in scale between the BIFT changes and those from the other scenarios.
} 
which labour supply reactions are explicitly taken into account. Instead of following the usual approach à la Hausman, we estimate the direct utility function using the methodology proposed by Van Soest (1995), on a sample of Spanish households taken from the 1995 wave of the EC Household Panel.

We shown that the scenarios simulated have only little impact on the efficiency of the economy (as measured by labour supply effects). The welfare effects of VMFT reforms are limited. On the contrary, BIFT schemes lead to considerable improvements in the welfare of the poorest households (and thus social welfare). These results are robust to different social welfare evaluation techniques.

In our opinion, the contributions of this paper are both methodological and policy oriented. From a methodological point of view this paper represents the first attempt to estimate labour supply reactions of Spanish households via a discrete choice approach, and also the first attempt to implement a comprehensive (i.e. mixing behavioural and arithmetical microsimulation) evaluation of the welfare effects of tax reforms. We have pointed out the limits and the shortcuts of this type of analysis but, at the same time we have shown that behavioural microsimulation models are powerful tools for the ex ante evaluation of public policies.

With respect to policy, the main contribution of this paper consists in highlighting the potential of a basic income - flat tax scheme as an institutional redistribution mechanism which can both reduce inequality and increase in social welfare in Spain. Its feasibility depends on the associated efficiency costs (in terms of reductions in labour supply) that may result: given the results of our econometric estimations, it seems that these costs are small.

\section{References}

Aaberge R., Colombino U. and Strom S. (1995), "Labor Supply Responses and Welfare Effects of Tax Reforms”, Scandinavian Journal of Economics 97, 635-659.

Aaberge R., Colombino U. and Strom S. (2000), "Welfare Effects of Proportional Taxation: Empirical Evidence from Italy, Norway and Sweden”, forthcoming Journal of Population Economics.

Aaberge R., Colombino U. and Vennemo, T. (2005), "Evaluating Alternative Representations of the Choice Sets in Models of Labour Supply", mimeo.

Agencia Tributaria (2001) “Informe anual de recaudación tributaria” Servicio de auditoría interna.

Anuario de Estadísticas Laborales y de Asuntos Sociales (2002), del Ministerio de Trabajo y Asuntos Sociales.

Arellano, M., Bover, O. and Labeaga, J. M. (1999), “Autoregressive Models with Sample Selectivity for Panel Data” chapter 2 in Hsiao, C., K. Lahiri, L.F. Lee and M.H. Pesaran (eds), Analysis of Panels and Limited Dependent Variable Models, Cambridge University Press.

Atkinson A.B. (1995), Public Economics in Action: A Basic Income-Flat Tax Proposal, Clarendon Press Oxford. Auten, G. and Carroll, R. (1999), "The Effect of Income Taxes on Household Income", Review of Economics and Statistics 81, 681-693.

Bargain (2005), “On Modelling Household Labour Supply with Taxation”, IZA DP No. 1455

Bingley P. and Walker I. (1997), “The Labour Supply, Unemployment and Participation of Lone Mothers in InWork Transfer Programmes”, The Economic Journal, 107, 1375-90. 
Blundell R., Duncan A, McCrae J. and Meghir C. (2000), “The Labour Market Impact of the Working FamiliesTax Credit”, Fiscal Studies 21, 75-104.

Bonin, H., Kempe, W., and Schneider, H. (2002), "Household labour supply effects of low-wage subsidies in Germany”, IZA DP, No. 637.

Bourguignon F. and Spadaro A. (2005), “Microsimulation as a Tool for Evaluating Redistribution Policies”, forthcoming Journal of Economic Inequality.

Cantó O., Gago A., Gradín C., Del Río C., (2002), “La política fiscal en España durante el periodo 1982-1996”, Hacienda Pública Española, special issue, 253-288.

Castañer J.M., Onrubia, J. and Paredes, R. (2000), "Efectos de la reforma del IRPF sobre la renta disponible, su distribución y sobre el bienestar social”, Economistas 84, 183-199.

Castañer, J.M., Romero, D. and Sanz, J.F. (2004), "Simulación sobre los hogares españoles de la reforma de IRPF de 2003. Efectos sobre oferta laboral, recaudación, distribución y bienestar”, XI Encuentro de Economía Pública, Barcelona, February 5th and 6th, 2004.

Creedy, J. and Duncan, A.S. (2002), "Behavioural microsimulation with labour supply responses”, Journal of Economic Surveys 16, 1-39.

Das, M. and Van Soest, A. (2000), "Family labour supply and proposed tax reforms in the Netherlands", forthcoming De Economist.

Feldstein, M. (1995), “The Effect of Marginal Tax Rates on Taxable Income: A Panel Study of the 1986 Tax Reform Act”, Journal of Political Economy 103, 551-572.

García, J. and Suárez, M. J. (2002), “La reforma del IRPF y la oferta laboral de las mujeres casadas”, Revista de Economía Aplicada 10, 53-77.

Gruber, J. and Saez, E. (2002), “The elasticity of taxable income: evidence and implications” Journal of Public Economics 84, 1-32.

Hausman J. (1981), "Labour Supply”, in Aaron and Pechman (eds.), How Taxes affect Economic Behaviour, Washington DC, The Brooking Institution.

Hausman J., (1985a), “The Econometrics of Nonlinear Budget Sets”, Econometrica 53, 1255-1282.

Hausman J., (1985b), “Taxes and Labour Supply” in Auerbach A. and Feldstein M. (eds.), Handbook of Public Economics, Vol. 1, Amsterdam. North Holland.

Hoynes H. (1996), "Welfare Transfers in Two Parent Families: Labour Supply and Welfare Participation Under AFDC-UP”, Econometrica 64, 295- 332.

Keane M. and Moffit, R. (1998), “A Structural Model of Multiple Welfare Program Participation and Labour Supply”, International Economic Review 39, 553-589.

King, M. (1983), "Welfare Analysis of Tax Reforms Using Household Data”, Journal of Public Economics, 21, 183-214.

Labeaga, J.M. and Sanz, J.F. (2001), “Oferta de trabajo y fiscalidad en España. Hechos recientes y tendencias tras el nuevo Impuesto sobre la Renta de las Personas Físicas”, Papeles de Economía Española 87, 230-243.

Levy, H. and Mercader-Prats, M., (2002), "Simplifying the personal income tax system: lessons from the 1998 Spanish Reform”, Fiscal Studies 23, 419-443.

MaCurdy, T.E. (1992), "Work disincentive effects of taxes: a re-examination of some evidence", American Economic Review 24, 265-289.

MaCurdy T., Green D and Paarsch H. (1990), “Assessing Empirical Approaches for Analyzing Taxes and Labour Supply”, Journal of Human Resources 25, 415-490.

Memoria de la Administración Tributaria (2001), Ministerio de Economía y Hacienda. Secretaría de Estado de Hacienda.

Mirrlees J.A, (1971), “An Exploration of the Theory of Optimal Income Taxation”, Review of Economic Studies 39, 175-208.

Oliver X. and Spadaro, A. (2003), “¿Renta mínima o mínimo vital? Un análisis sobre los efectos redistributivos de posibles reformas del sistema impositivo español”. DEA Working Paper Series $n^{\circ} 1$. Universitat de les Illes Balears. Available at http://www.uib.es/depart/deaweb/deawp/

Oliver X. and Spadaro, A. (2004a), "A Technical Description of GLADHISPANIA: A Spanish MicroSimulation Tax-Benefit Model” DEA Working Paper Series $n^{\circ} 7$. Universitat de les Illes Balears. Available at http://www.uib.es/depart/deaweb/deawp/

Oliver X. and Spadaro, A. (2004b), "Are Spanish Governments Really Averse to Inequality? A Normative Analysis using the 1999 Spanish Tax Reform", Investigaciones Económicas 28, 551-566.

Prieto, J., and Álvarez, S. (2002), “Análisis de las ganancias de bienestar asociadas a los efectos de la reforma del IRPF sobre la oferta laboral de la familia española”, Instituto de Estudios Fiscales, DT 7.

Sanchís, J.A., and Sanchís, A.S. (2001), “Análisis de simulación de los efectos distributivos de la reforma del IRPF de 1999” in Labeaga, J.M. and M. Mercader-Prats (eds.), Desigualdad, redistribución y bienestar: una aproximación a partir de la microsimulación de reformas fiscales, Instituto de Estudios Fiscales, Madrid. 
Stern, N. (1976), “On the specification of models of optimum income taxation” Journal of Public Economics 6, 123-162.

Stern, N. (1986), “On the Specification of Labour Supply Functions”, in Blundell, R. and Walker, I. (eds.), Unemployment, Search and Labour Supply, Cambridge University Press.

Van Soest A. (1995), "Structural Models of Family Labour Supply. A Discrete Choice Approach”, Journal of Human Resources, 30, 63-88. 
Figure 1: Weekly hours of work of the singles and the couples (head of the household and spouse)

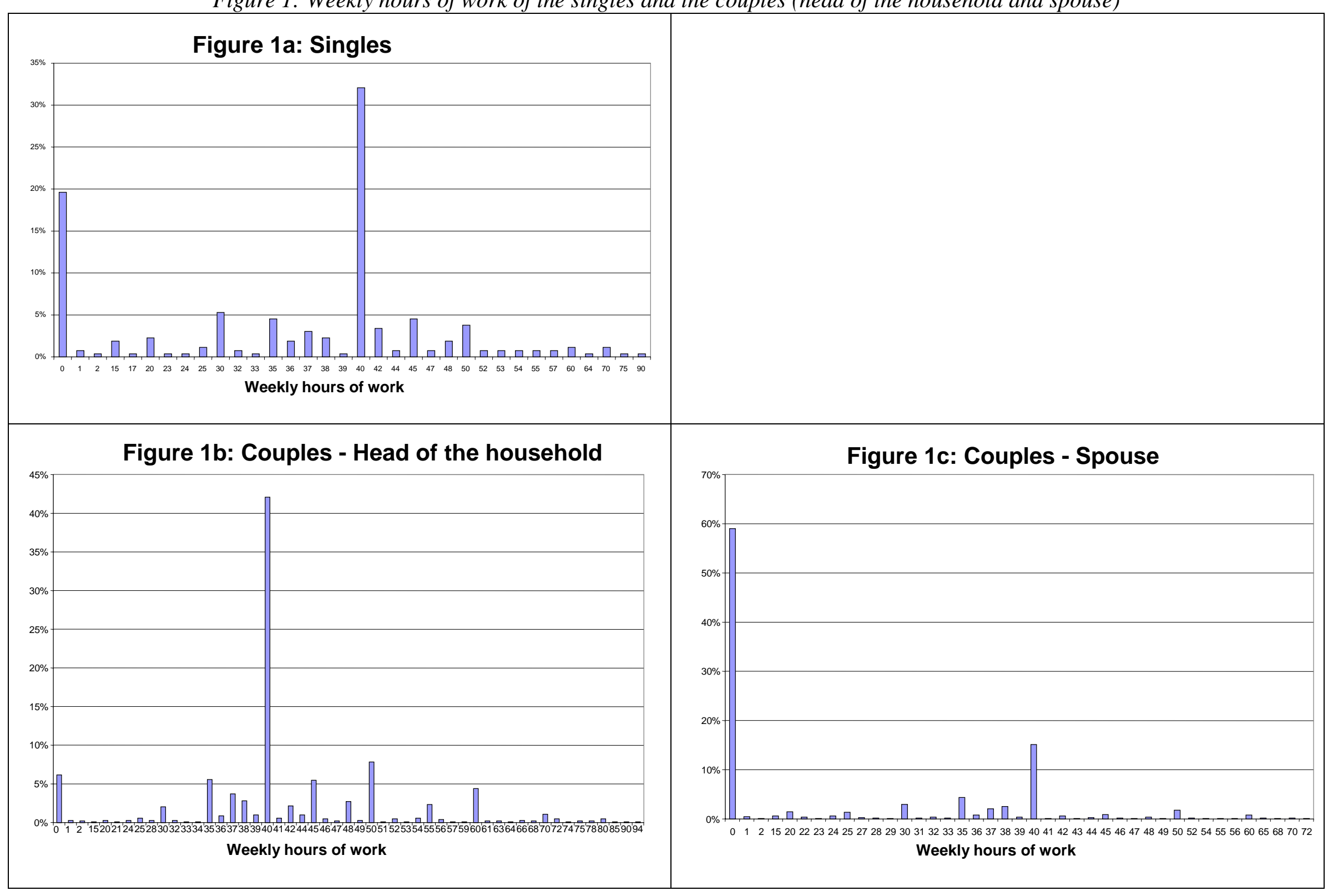


Figure 2: Winners and losers (Whole sample)

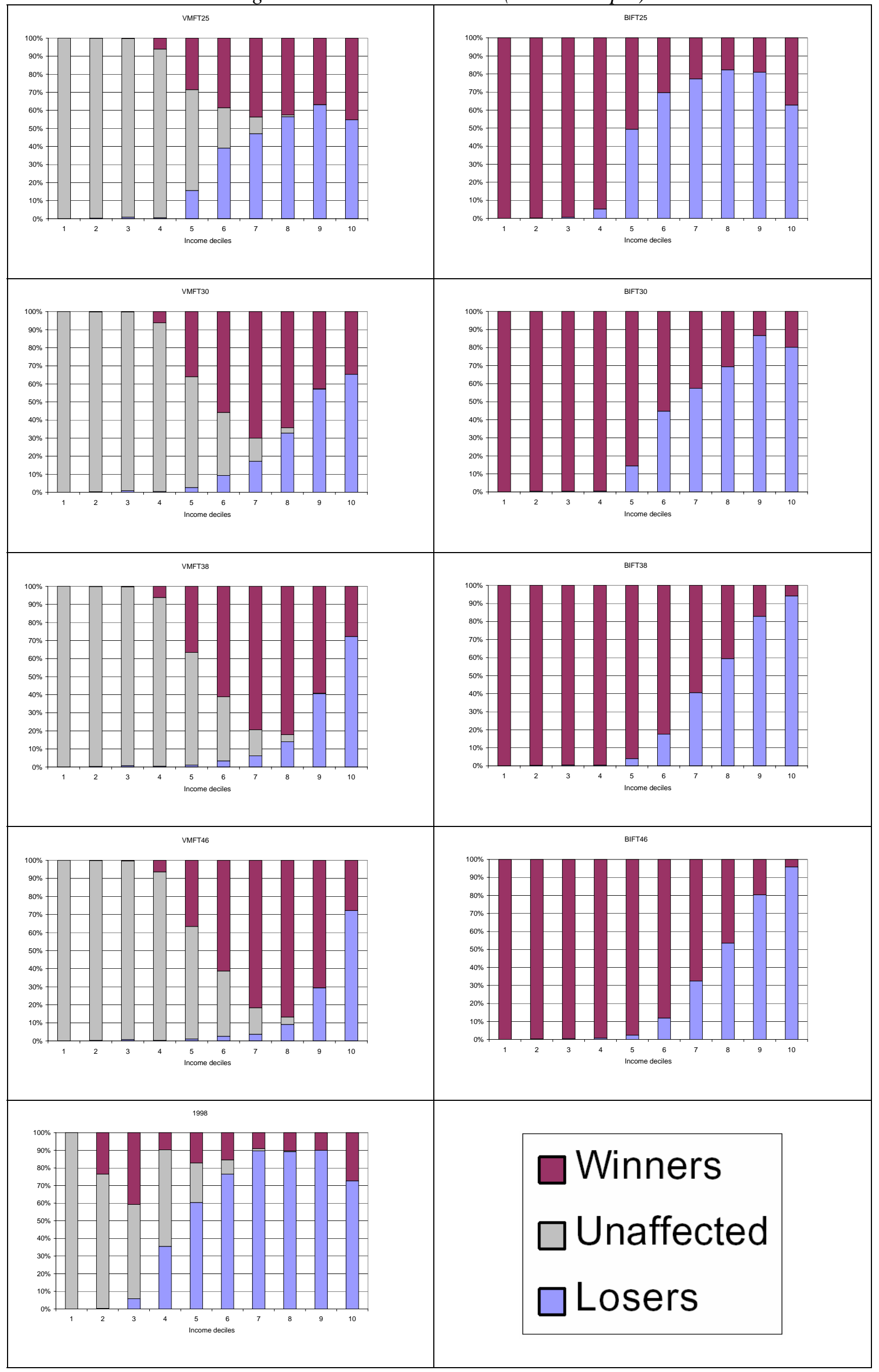


Figure 3: Social welfare variations with respect to the reference scenario (1999). Whole sample

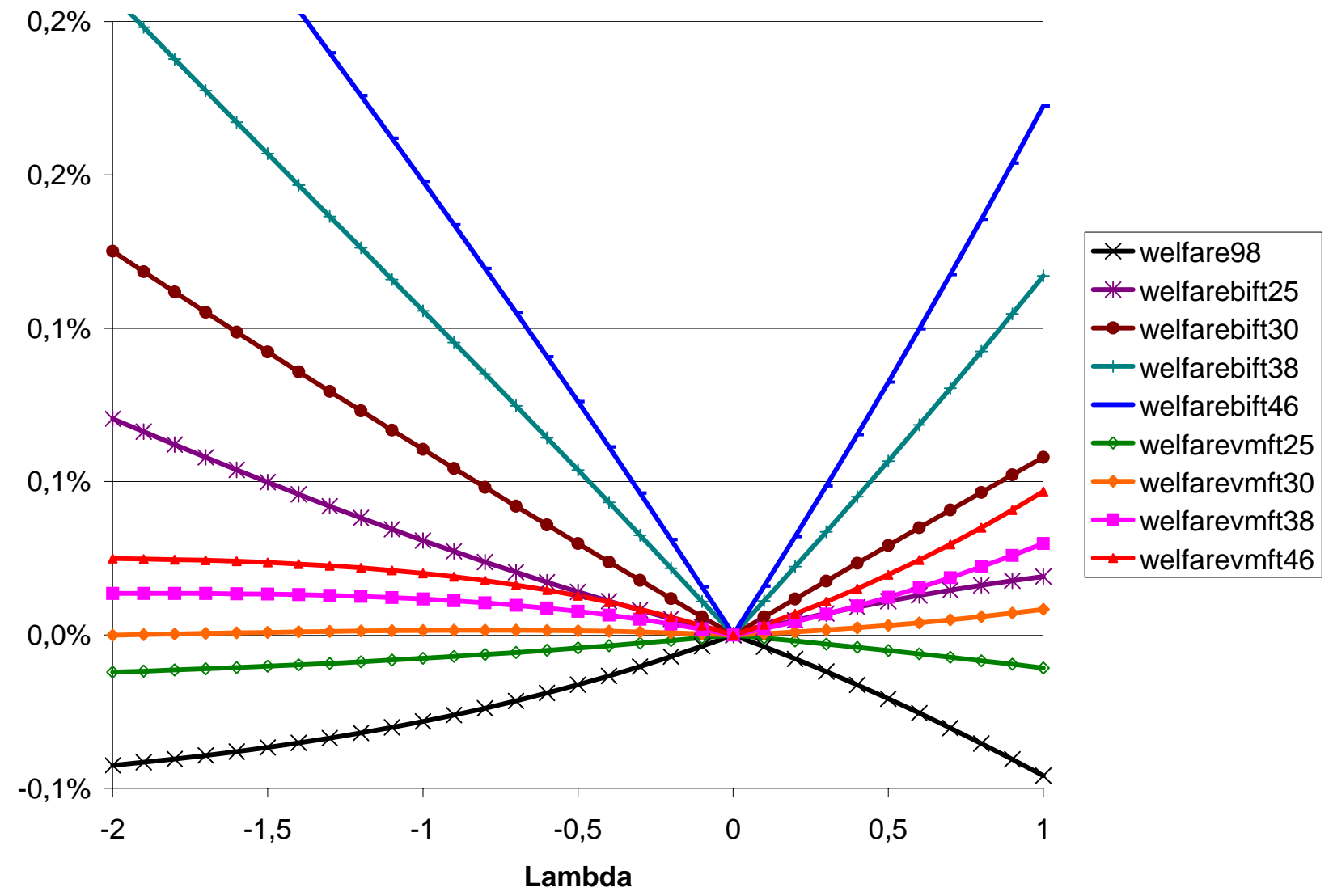

Figure 4a: Social welfare variation using equivalent incomes (with respect to the reference scenario, 1999). Whole sample

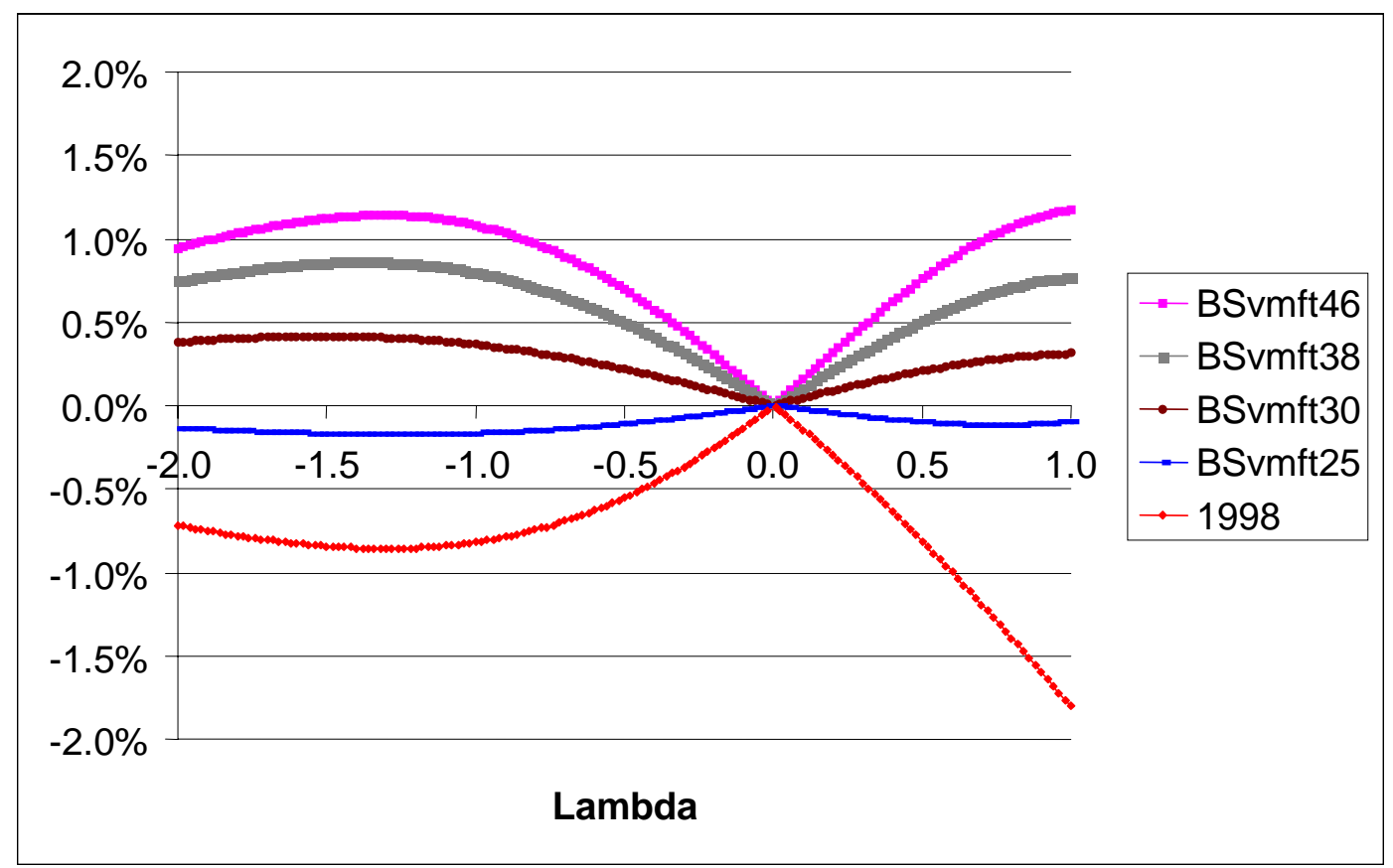


Figure 4b: Social welfare variation using equivalent incomes (with respect to the reference scenario, 1999). Whole sample

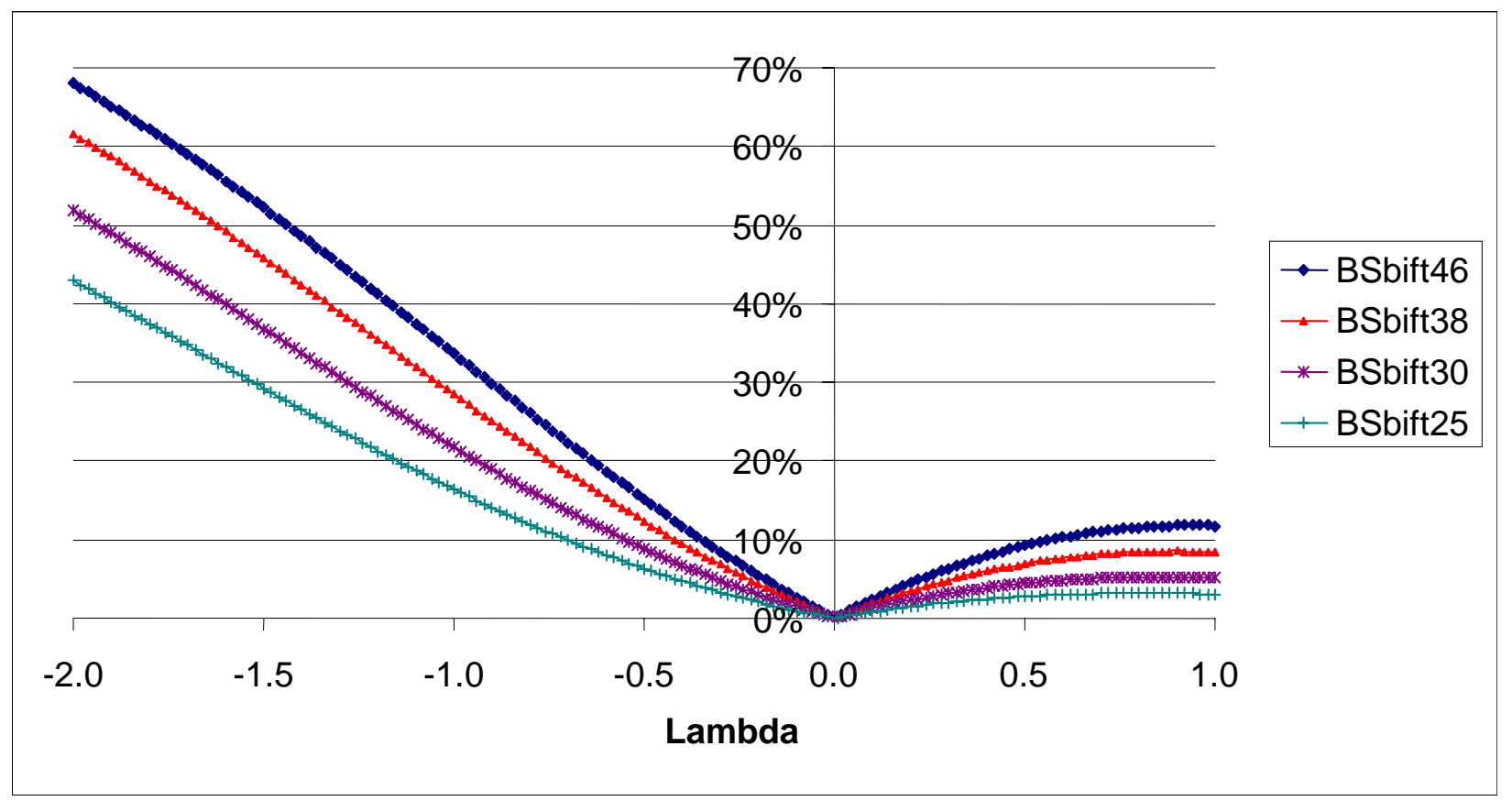


Table 1: Comparison of updated 1995 ECHP with 1998 and 1999 ECHP (in euros)

\begin{tabular}{cccc}
\hline Household mean disposable income PHOGUE & $\begin{array}{c}\text { PHOGUE 1995 } \\
\text { (updated) }\end{array}$ & Difference \\
\hline 1998 & 18,334 & $18,130.6$ & $-1.11 \%$ \\
1999 & 18,375 & 19,311 & $5.09 \%$ \\
\hline
\end{tabular}

Table 2: Calibration of GLADHISPANIA (in billions of euros)

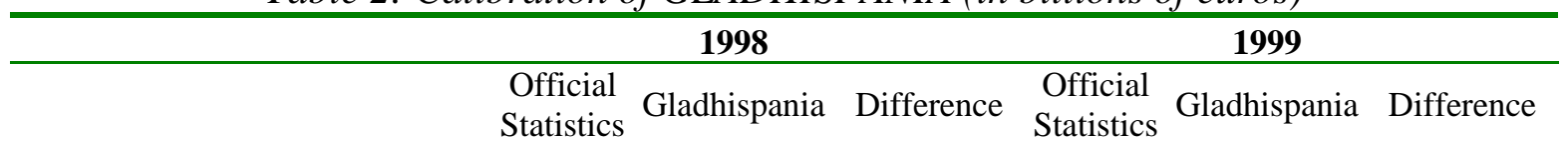

\begin{tabular}{|c|c|c|c|c|c|c|}
\hline & (1) & (2) & $(3)=(2-1) / 1$ & (4) & (5) & $(6)=(5-4) /$ \\
\hline Personal Income Tax collection ${ }^{(\mathrm{a}}$ & 39.2 & 39.1 & $-0.25 \%$ & 39.54 & 37.83 & $-4.33 \%$ \\
\hline $\begin{array}{l}\text { Average income Tax rate }{ }^{(c)} \\
=(\text { net tax/ taxable income) }\end{array}$ & $15.13 \%$ & $15.59 \%$ & $3.03 \%$ & $23.15 \%$ & $23.87 \%$ & $3.12 \%$ \\
\hline Employee Social & & & & & & \\
\hline Security contributions ${ }^{(b)}$ & 13.7 & 13.37 & $-2.40 \%$ & 2,424 & 14.26 & $-2.13 \%$ \\
\hline
\end{tabular}

(a) Source: Informe Anual de Recaudación Tributaria de 2001; (b) Source: Anuario de Estadísticas Labourales y de Asuntos Sociales 2002; (c) Source: Memoria de la Administración Tributaria 2001

Table 3: Descriptive statistics of the variables used in the econometric section.

SINGLES

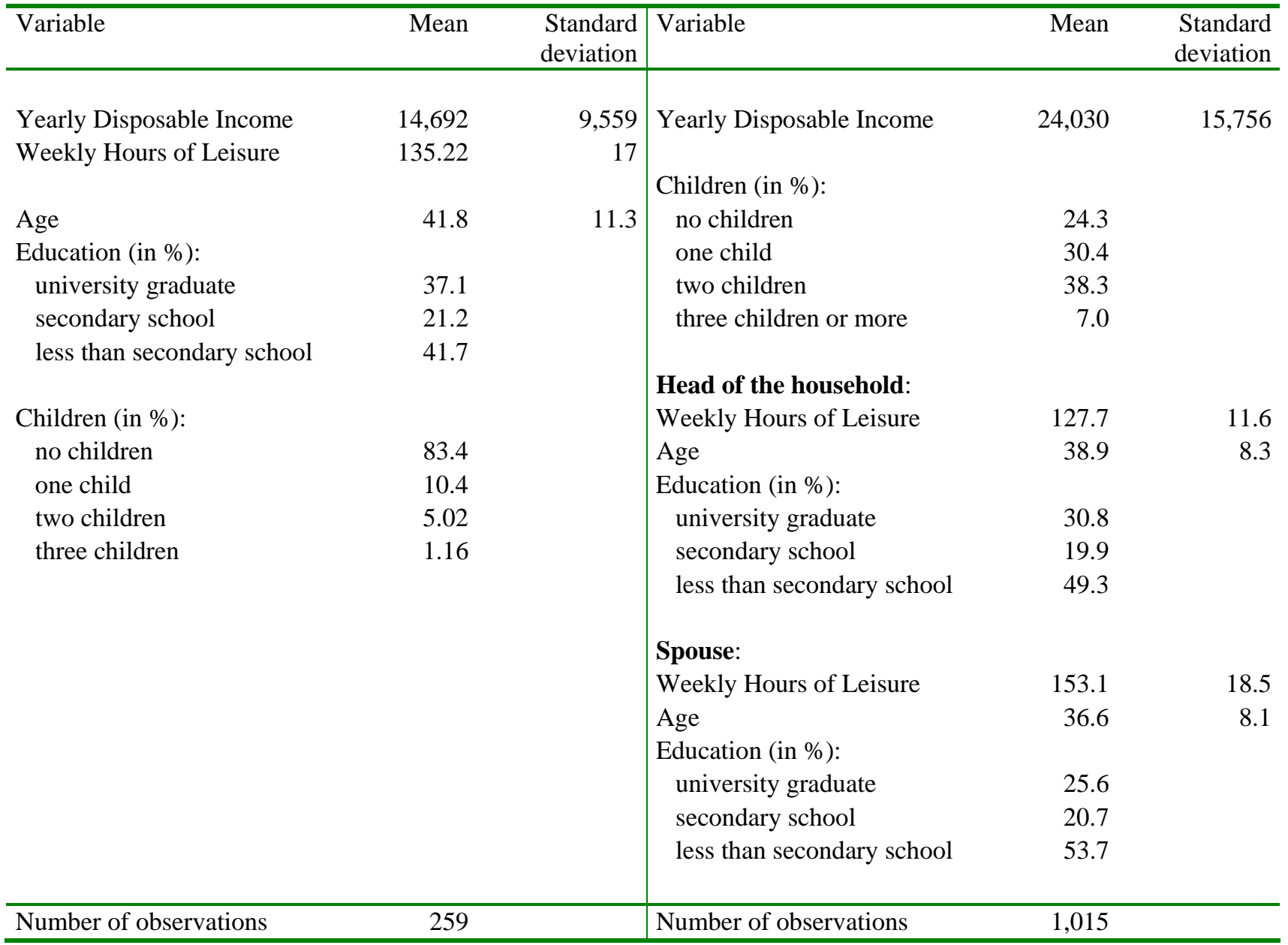

Table 4: Social Security contribution and Monthly Minimum and Maximum Base (in euros)

\begin{tabular}{|c|c|c|c|c|c|c|}
\hline Minimum base & \multicolumn{3}{|c|}{$\begin{array}{c}1998 \\
477(=\text { minimum } \\
\text { wage } / 12)\end{array}$} & \multirow{2}{*}{\multicolumn{3}{|c|}{$\begin{array}{c}1999 \\
485.7(=\text { minimum } \\
\text { wage } / 12) \\
2,402.7\end{array}$}} \\
\hline \multirow[t]{2}{*}{ Maximum base } & \multicolumn{3}{|c|}{2,360} & & & \\
\hline & \multicolumn{2}{|c|}{ Firm } & \multicolumn{2}{|c|}{ Worker } & \multicolumn{2}{|c|}{ Total } \\
\hline Contribution Items & 1998 & 1999 & 1998 & 1999 & 1998 & 1999 \\
\hline
\end{tabular}




\begin{tabular}{|c|c|c|c|c|c|c|}
\hline General contingencies & $23.6 \%$ & $23.6 \%$ & $4.7 \%$ & $4.7 \%$ & $28.3 \%$ & $28.3 \%$ \\
\hline $\begin{array}{l}\text { Mean no. of industrial accidents and professional } \\
\text { illnesses }\end{array}$ & $4 \%$ & $4 \%$ & $0 \%$ & $0 \%$ & $4 \%$ & $4 \%$ \\
\hline \multicolumn{7}{|l|}{ Unemployment } \\
\hline Full-time worker (permanent worker) & $6.2 \%$ & $6.2 \%$ & $1.6 \%$ & $1.6 \%$ & $7.8 \%$ & $7.8 \%$ \\
\hline Full-time worker (temporary worker) & $6.2 \%$ & $6.7 \%$ & $1.6 \%$ & $1.6 \%$ & $7.8 \%$ & $8.3 \%$ \\
\hline Part time worker & $6.2 \%$ & $7.7 \%$ & $1.6 \%$ & $1.6 \%$ & $7.8 \%$ & $9.3 \%$ \\
\hline Social welfare fund & $0.4 \%$ & $0.4 \%$ & $0 \%$ & $0 \%$ & $0.4 \%$ & $0.4 \%$ \\
\hline Professional training & $0.6 \%$ & $0.6 \%$ & $0.1 \%$ & $0.1 \%$ & $0.7 \%$ & $0.7 \%$ \\
\hline
\end{tabular}

Table 5: Tax rates schedule (in euros)

\begin{tabular}{|c|c|c|c|c|c|}
\hline \multicolumn{4}{|c|}{1998} & \multirow{2}{*}{\multicolumn{2}{|c|}{$\begin{array}{c}1999 \\
\begin{array}{c}\text { Single person's and family income } \\
\text { tax return }\end{array}\end{array}$}} \\
\hline \multicolumn{2}{|c|}{$\begin{array}{c}\text { Single Person's income tax } \\
\text { return }\end{array}$} & \multicolumn{2}{|c|}{ Family income tax return } & & \\
\hline Bracket & Tax rate & Bracket & Tax rate & Bracket & Tax rate \\
\hline $0-2,806.73$ & 0 & $0-5,415.12$ & 0 & $0-3,606.07$ & 0.18 \\
\hline 2,806.73-6,977.75 & 0.2 & 5,415.12-13,492.72 & 0.2 & 3,606.07-12,621.25 & 0.24 \\
\hline $6,977.75-13,793.23$ & 0.23 & $13,492.72-19,028.04$ & 0.246 & $12,621.25-24,641.50$ & 0.283 \\
\hline $13,793.23-21,005.37$ & 0.28 & $19,028.04-26,390.44$ & 0.29 & $24,641.50-39,666.08$ & 0.372 \\
\hline $21,005.37-30,621.57$ & 0.32 & $26,390.44-35,255.37$ & 0.33 & $39,666.08-66,111.33$ & 0.45 \\
\hline $30,621.57-40,838.77$ & 0.39 & $35,255.37-47,485.97$ & 0.39 & $>66,111.33$ & 0.48 \\
\hline 40,838.77-51,837.29 & 0.45 & $47,485.97-59,716.56$ & 0.45 & & \\
\hline $51,837.29-63,106.27$ & 0.52 & $59,716.56-72,938.83$ & 0.53 & & \\
\hline$>63,106.27$ & 0.56 & $>72,938.83$ & 0.56 & & \\
\hline
\end{tabular}

Table 6: Advantages and disadvantages of the reforms based on a flat tax

\begin{tabular}{|c|c|}
\hline Advantages & Disadvantages \\
\hline $\begin{array}{l}\text { Eliminating all the current } \\
\text { allowances and deductions would } \\
\text { broaden the tax base. Then, all } \\
\text { sources of income are treated } \\
\text { equally (horizontal equity). }\end{array}$ & $\begin{array}{l}\checkmark \text { These schemes can affect labour } \\
\text { supply of the more productive } \\
\text { people if the flat tax is too high }\end{array}$ \\
\hline $\begin{array}{l}\checkmark \text { Simplicity for taxpayers, and } \\
\text { consequently, more transparency, } \\
\text { since all income is taxed at the } \\
\text { same rate) }\end{array}$ & $\begin{array}{l}\checkmark \text { High rates can cause capital flows } \\
\text { toward other countries with better } \\
\text { capital fiscal treatment }\end{array}$ \\
\hline $\begin{array}{l}\text { Simplicity for the Treasury } \\
\text { Department, and thus, minor } \\
\text { collection costs and less tax evasion }\end{array}$ & $\begin{array}{ll}\checkmark & \text { Lower flat taxes can generate } \\
\text { redistribution towards the rich }\end{array}$ \\
\hline
\end{tabular}

Table 7: BIFT and VMFT: simulated scenarios (in euros)

\begin{tabular}{ccc}
\hline & BIFT & VMFT \\
\hline Flat tax & Basic Income & Vital Minimum \\
\hline $46 \%$ & 4,632 & 13,997 \\
$38 \%$ & 3,526 & 12,002 \\
$30 \%$ & 2,421 & 9,589 \\
$25 \%$ & 1,730 & 7,737 \\
\hline
\end{tabular}

Table 8: New typology of households

\begin{tabular}{lrr}
\hline & Total households & $\begin{array}{r}\text { Potential } \\
\text { workers }\end{array}$ \\
\hline Singles & 1000 & 259 \\
Couples & 3,195 & 1,015 \\
Other households & & \\
$\quad$ Fiscal unit treated as couples & 1,852 &
\end{tabular}




\begin{tabular}{lll}
\hline Total & 9,812 & 1,274 \\
\hline
\end{tabular}

Table 9: Singles estimation

\begin{tabular}{|c|c|c|}
\hline Variable & Coefficient & Standard error \\
\hline Income $^{2}$ & -0.41 & 0.50 \\
\hline Hours of leisure ${ }^{2}$ & -236.95 & 32.44 \\
\hline Income $\mathrm{x}$ Hours of leisure & 29.06 & 5.81 \\
\hline Income & -25.54 & 6.77 \\
\hline x Age & 0.50 & 0.25 \\
\hline $\mathrm{x}$ Education & 0.04 & 0.84 \\
\hline x Children & 0.19 & 0.16 \\
\hline Hours of leisure & 458.94 & 65.24 \\
\hline$x$ Age & -0.49 & 1.53 \\
\hline x Educ1 & -4.19 & 3.93 \\
\hline x Educ2 & 0.39 & 2.89 \\
\hline Fixed costs & 2.40 & 0.50 \\
\hline Number of observations & 259 & \\
\hline Log likelihood & -273.84 & \\
\hline
\end{tabular}

Table 10: Couples estimation

\begin{tabular}{|c|c|c|}
\hline Variable & Coefficient & Standard Error \\
\hline Income $^{2}$ & -0.71 & 0.16 \\
\hline Hours of leisure of the household's head ${ }^{2}$ & -83.69 & 6.30 \\
\hline Hours of leisure of the spouse ${ }^{2}$ & 91.98 & 8.01 \\
\hline Income $x$ Hours of leisure of the household's head & -2.74 & 1.51 \\
\hline Income $x$ Hours of leisure of the spouse & -1.69 & 1.01 \\
\hline Hours of leisure of the household's head $x$ Hours of leisure of the spouse & -44.8 & 7.98 \\
\hline Income & 8.20 & 2.37 \\
\hline $\mathrm{x}$ Age of the household's head & -0.60 & 0.48 \\
\hline$x$ Age of the spouse & 1.54 & 0.55 \\
\hline$x$ Age of the spouse ${ }^{2}$ & -0.63 & 0.19 \\
\hline Hours of leisure of the household's head & 197.53 & 17.25 \\
\hline x Education of the household's head & -5.68 & 1.81 \\
\hline x Age of the household's head & 2.19 & 0.67 \\
\hline Hours of leisure of the spouse & -117.38 & 17.65 \\
\hline $\mathrm{x}$ Education of the spouse & -11.1 & 1.20 \\
\hline$x$ Age of the spouse & 2.02 & 0.61 \\
\hline x 1(one dependent child) & 2.82 & 0.95 \\
\hline x 1(two or more dependent children) & 5.05 & 0.90 \\
\hline Fixed costs & -0.35 & 0.26 \\
\hline Number of observations & 1024 & \\
\hline Log likelihood & -1553.81 & \\
\hline
\end{tabular}

Note. The variables have been rescaled in the following way: Income $=$ disposable income in euros/30000; Hours of leisure $=(24 \mathrm{x} 7$ - weekly hours of work $) / 160$; Age = (age in years -38$) / 10$; Education = average number of years of study $/ 10$ 
Table 11: Singles transition matrixes (the reference system is the one of 1999)

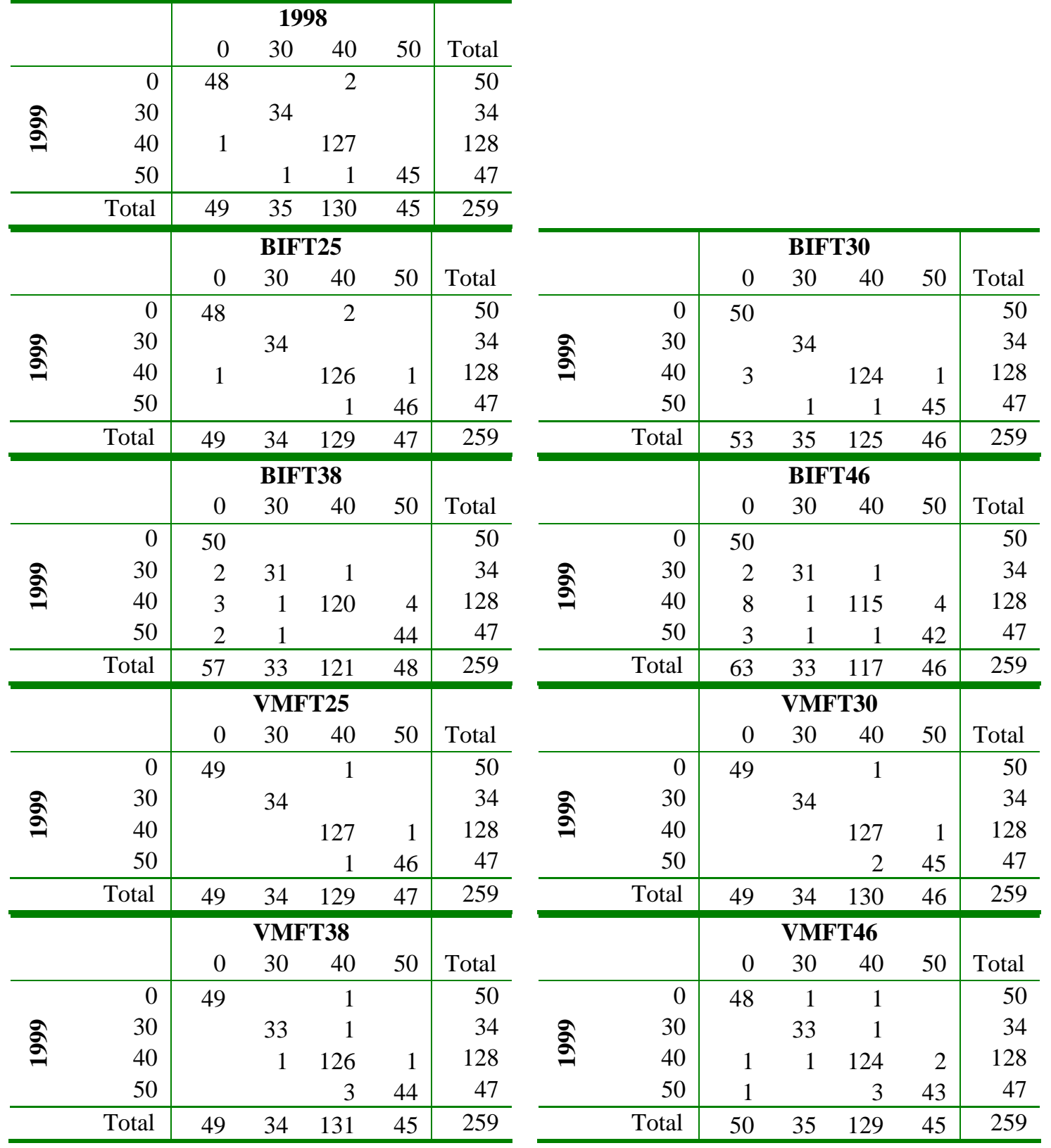


Table 12: Couples transition matrixes (the reference system is the one of 1999)

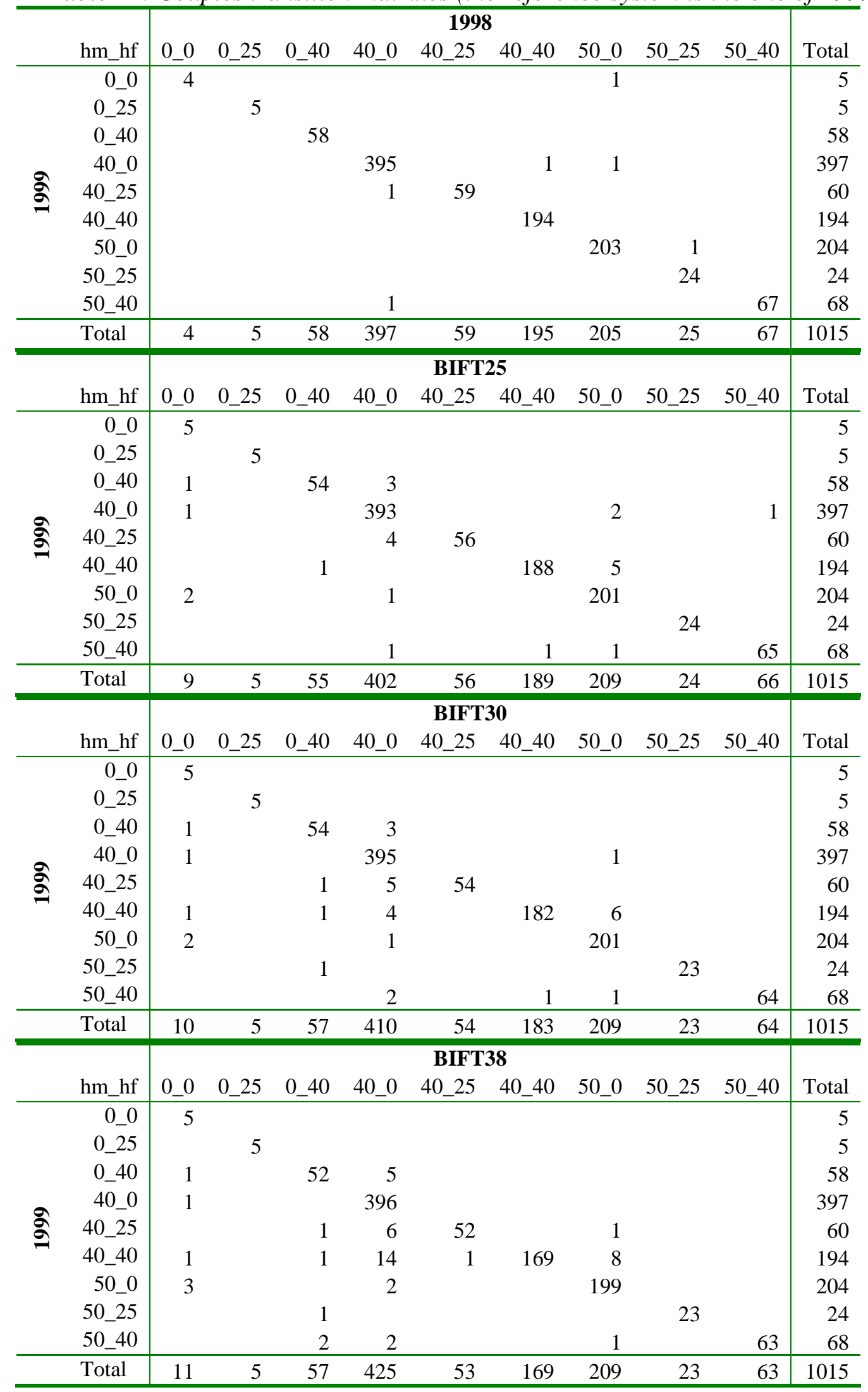


Table 12: Couples transition matrixes (the reference system is the one of 1999) [cont.]

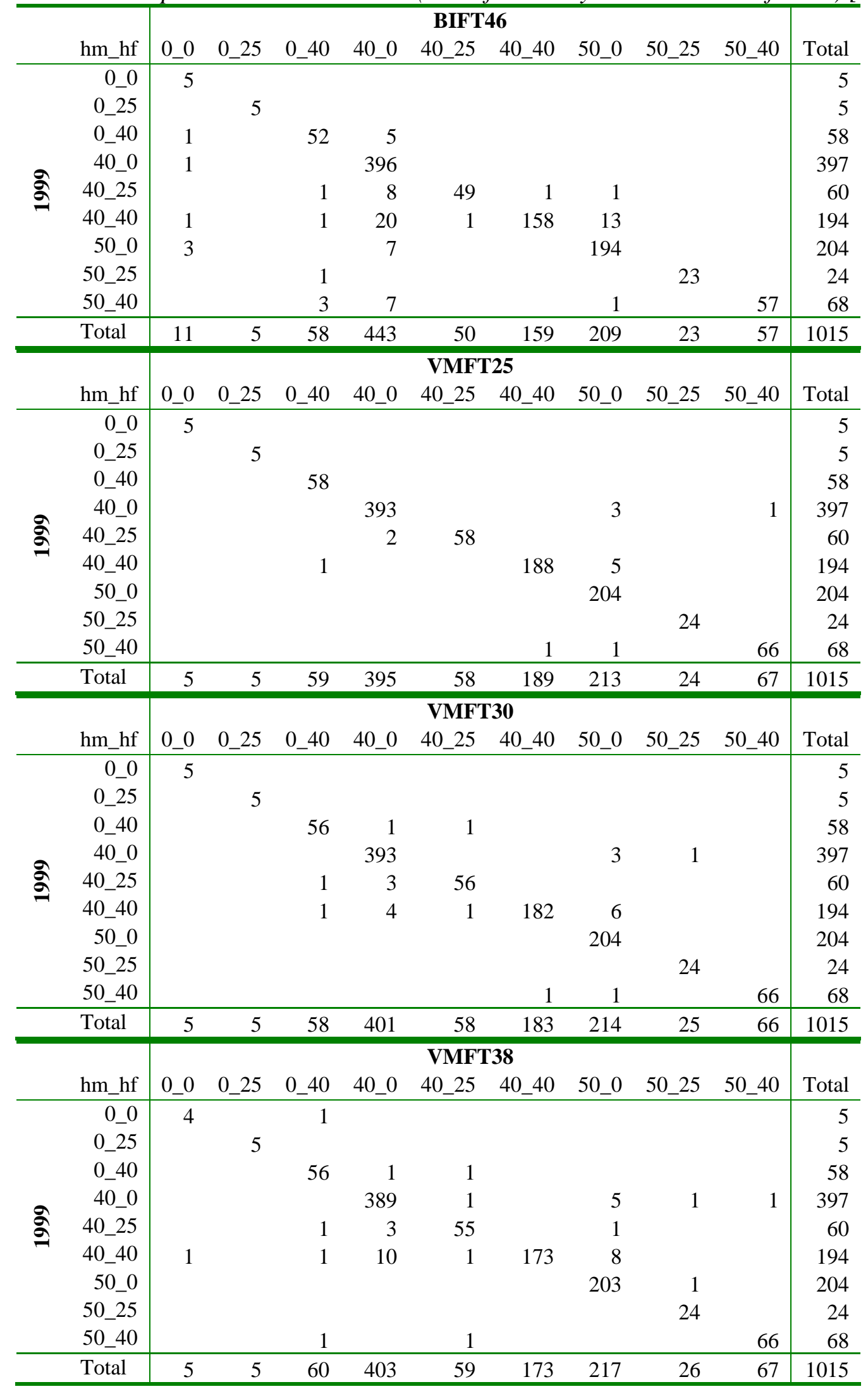


Table 12: Couples transition matrixes (the reference system is the one of 1999). Cont.

\begin{tabular}{|c|c|c|c|c|c|c|c|c|c|c|c|}
\hline \multirow{2}{*}{\multicolumn{2}{|c|}{ Hm_hf }} & \multicolumn{9}{|c|}{ VMFT46 } & \multirow[b]{2}{*}{ Total } \\
\hline & & 0_0 & 0_25 & 0_40 & 40_0 & 40_25 & 40_40 & 50_0 & 50_25 & 50_40 & \\
\hline \multirow{10}{*}{ gे } & 0_0 & 4 & & 1 & & & & & & & 5 \\
\hline & 0_25 & & 5 & & & & & & & & 5 \\
\hline & 0_40 & & & 56 & 1 & 1 & & & & & 58 \\
\hline & 40_0 & & & & 388 & 1 & 1 & 5 & 1 & 1 & 397 \\
\hline & 40_25 & & & 1 & 4 & 54 & 1 & & & & 60 \\
\hline & 40_40 & 1 & & & 13 & 1 & 170 & 9 & & & 194 \\
\hline & 50_0 & & & & 2 & & & 201 & 1 & & 204 \\
\hline & 50_25 & & & & & & & & 24 & & 24 \\
\hline & 50_40 & & & 2 & 1 & & 1 & & & 64 & 68 \\
\hline & Total & 5 & 5 & 60 & 409 & 57 & 173 & 215 & 26 & 65 & 1015 \\
\hline
\end{tabular}

Table 13: Equivalent variations (in euros)

\begin{tabular}{|c|c|c|c|c|c|c|c|c|c|}
\hline & 1998 & \multicolumn{2}{|c|}{$46 \%$} & \multicolumn{2}{|c|}{$38 \%$} & \multicolumn{2}{|c|}{$30 \%$} & \multicolumn{2}{|c|}{$25 \%$} \\
\hline & (1) & (2) & (3) & (4) & (5) & (6) & (7) & (8) & (9) \\
\hline Decile & $\begin{array}{c}\text { Disposable } \\
\text { income }\end{array}$ & $\begin{array}{c}\text { BIFT } \\
(4,632)\end{array}$ & $\begin{array}{c}\text { VMFT } \\
(13,997)\end{array}$ & $\begin{array}{c}\text { BIFT } \\
(3,526)\end{array}$ & $\begin{array}{c}\text { VMFT } \\
(12,002)\end{array}$ & $\begin{array}{c}\text { BIFT } \\
(2,421)\end{array}$ & $\begin{array}{l}\text { VMFT } \\
(9,589)\end{array}$ & $\begin{array}{c}\text { BIFT } \\
(1,730)\end{array}$ & $\begin{array}{l}\text { VMFT } \\
(7,737)\end{array}$ \\
\hline 1 & 0 & 4,729 & 0 & 3,600 & 0 & 2,472 & 0 & 1,767 & 0 \\
\hline 2 & 1 & 4,441 & 0 & 3,353 & 3 & 2,264 & 1 & 1,590 & 0 \\
\hline 3 & 6 & 3,099 & 0 & 2,227 & 0 & 1,351 & 2 & 811 & 0 \\
\hline 4 & -31 & 2,452 & 0 & 1,689 & 8 & 925 & 17 & 435 & 3 \\
\hline 5 & -150 & 2,134 & 115 & 1,396 & 104 & 641 & 92 & 213 & 7 \\
\hline 6 & -257 & 1,369 & 355 & 801 & 349 & 219 & 166 & -117 & -52 \\
\hline 7 & -301 & 717 & 688 & 324 & 482 & -86 & 208 & -291 & -90 \\
\hline 8 & -337 & -170 & 979 & -273 & 597 & -384 & 173 & -449 & -155 \\
\hline 9 & -407 & $-1,471$ & 823 & $-1,143$ & 259 & -779 & -132 & -629 & -312 \\
\hline 10 & -561 & $-4,011$ & $-1,638$ & $-2,436$ & -933 & -809 & -173 & 161 & 496 \\
\hline Mean & -204 & 1,328 & 132 & 953 & 87 & 581 & 35 & 349 & -10 \\
\hline
\end{tabular}

